\title{
Neurofibromatosis with congenital malformation of the spinal cord
}

\author{
A. J. BARSON AND F. M. COLE \\ From the Department of Pathology, University of Manchester
}

The first description of generalized neurofibromatosis has been attributed (Worster-Drought, Dickson, and McMenemey, 1937) to Tilesius in 1793 , though the disease is usually named after von Recklinghausen (1882). It was von Recklinghausen who first suggested that the many manifestations of this disease were not purely acquired, but were a 'growth perversion of the foetal neuroectoderm'. Later workers (Gardner and Frazier, 1930; Turner and Gardner, 1938) showed that the disease had a hereditary basis, being transmitted by a Mendelian dominant gene. It was also subsequently shown that the 'multiple neuromas' noted by von Recklinghausen were in fact derived not from nerve cells per se, but from the 'supportive or protective derivatives of the ectoderm within the substance of the nervous system' (Lichtenstein, 1949). Moreover, the relationship between von Recklinghausen's disease and other neuroectodermal dysplasias, especially tuberose sclerosis, Sturge-Weber, and von HippelLindau's diseases, came to be recognized. The term 'phakomatoses' was coined to describe this group of diseases by Van Der Hoeve (1932). Their embryological and morbid anatomical similarities have been re-emphasized more recently by Obrador (1963), and also by Willis (1965) who classified them as the 'hamartomatous syndromes'.

Willis (1965) postulated that such syndromes were the result of an enzyme deficiency, not unlike the many inborn errors of metabolism which have been documented, but which resulted in excessive growth of particular tissues. In this sense neurofibromatosis is a congenital malformation, although it rarely manifests itself before late childhood or adult life. On the other hand, one would expect that excessive growth of neuroectoderm in the embryo would occasionally result in a malformation present at birth. Tumours of the central nervous system arising in adult tissue are not uncommon in neurofibromatosis (Rodriguez and Berthrong, 1966). Yet a hamartomatous growth which, through its presence, has interfered with the normal development of the spinal cord has not to our knowledge been recorded in the literature.

This paper describes a case of spinal cord dysraphia with a localized overgrowth of nervous tissue which was detected during the post-mortem examination of a woman of 63 with von Recklinghausen's disease.

\section{CASE HISTORY}

The patient, a 63-year-old woman at the time of her death, first presented when she was 57 years old with a stress fracture of a metatarsal bone of her right foot. One year later she developed a similar fracture of the left foot. These features, together with a complaint of generalized bone pain, suggested a metabolic bone disorder. Examination showed severe cutaneous neurofibromatosis and biochemical and radiological investigations indicated that she was suffering from osteomalacia. This diagnosis was confirmed by bone biopsy, which also showed secondary osteitis fibrosa. She was treated with oral vitamin D (50,000 units per day) which improved her general condition and reduced the radiological and biochemical evidence of osteomalacia. Six months before her death she complained of weakness of both legs. She said that she could no longer rise from a sitting position without the aid of a support, and that this weakness had come on over the past few months. She denied any sensory disturbances.

Examination confirmed generalized loss of power in both legs, more severe on the right side. Knee and ankle tendon reflexes were symmetrically exaggerated. Both plantar responses were extensor but there was no sign of muscle wasting. Examination of the sensory system showed probable loss of all modalities below the hips, but it was difficult to be sure of this as the patient was a poor witness. Lumbar punctures revealed persistently raised cerebrospinal fluid protein levels $(80-90 \mathrm{mg} . / 100 \mathrm{ml}$.). The pressure was low $(50 \mathrm{~mm}$. water) with a poor rise and fall on jugular compression. Straight radiographs of the spine were normal apart from evidence of osteomalacia. A cysternal myelogram showed no obstruction in the spinal canal.

Before further investigation could be undertaken the patient started vomiting persistently. She had been troubled previously with a duodenal ulcer, and a barium meal showed that the ulcer was causing pyloric stenosis. During an operation to relieve the obstruction she suffered ventricular fibrillation, and although this was corrected a further episode 24 hours later caused her death.

NECROPSY At necropsy there was diffuse patchy pigmentation of the skin, and dozens of neurofibromata, 
the largest $5 \mathrm{~cm}$. in diameter. Many similar lesions were found on the serosal surface of the small intestine, the abdominal surface of the diaphragm, and within the substance of the pancreas. There was severe coronary artery atheroma but no occlusion or myocardial infarction.

Spine and spinal cord At the mid-thoracic region of the spinal cord there was a plaque of white matter $1.5 \mathrm{~cm}$. in its widest diameter and extending over $3 \mathrm{~cm}$. of the cord. It was situated on the right antero-lateral surface of the cord at the levels of T.5, 6, and 7. The anterior nerve roots showed no abnormality, but at the mid point of the plaque involving one segment there were three sets of posterior roots, two on the right and one on the left side. The two on the right were united until their immediate entry into the cord. The plaque was not attached to the meninges, and that portion of the cord immediately caudal to the lower edge of the lesion showed gross atrophy. The bony canal at this point lightly compressed the lesion, with obliteration of the subarachnoid space. The vertebrae at the level of the plaque showed no sign of malformation or fracture, but like the rest of the skeletal system were unusually porous and soft.

Serial sections of the cord lesion showed that the part

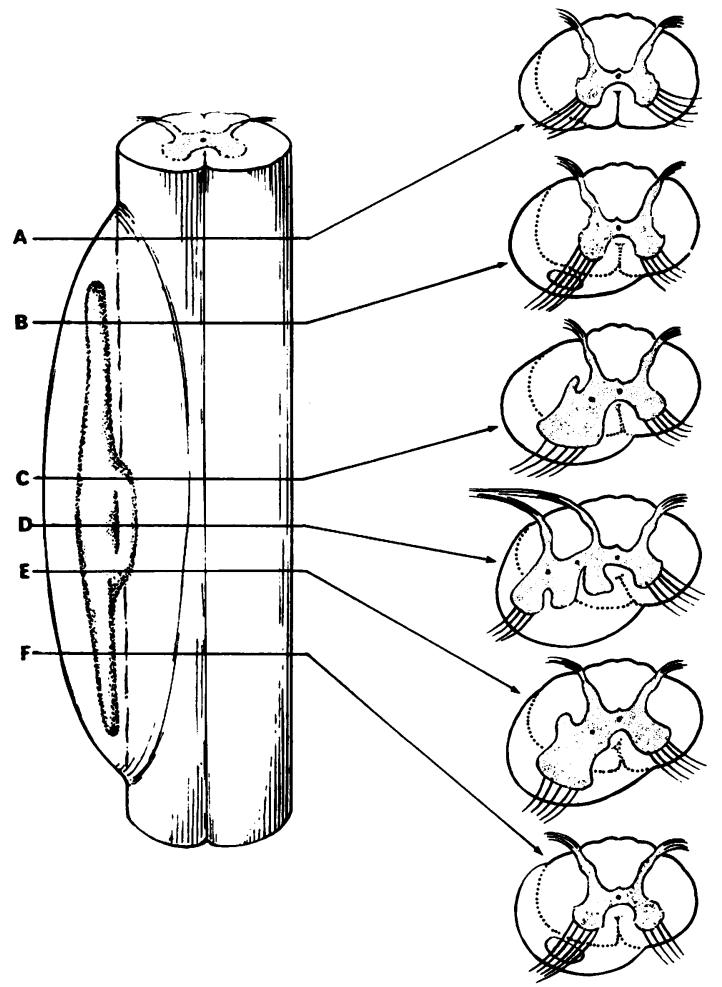

FIG. 1. Diagrammatic representation of the exterior of the spinal cord on the left, with its appearance on crosssection at different levels on the right. The hamartomatous lesion was situated on the right antero-lateral surface of the cord between T.5 and T.7. of the plaque which could be seen with the naked eye consisted of white matter containing grey matter, the latter taking the form of a "collar stud' (Fig. 1). At level A (Fig. 1) the expansion consisted of white matter only. At level B it contained a core of grey matter which increased ir: size as the sections were carried caudally, until at level $\mathbf{C}$ it joined the right anterior horn. At this point the central canal bifurcated and a third posterior horn began to appear. At level $\mathrm{D}$, which was situated midway along the length of the plaque, the cord was almost completely duplicated with four anterior and three posterior horns. Three lines of nerve rootlets, two on the right and one on the left side, were attached to these posterior horns, but only the two lateral anterior horns gave rise to motor roots. All the anterior horns here contained neurones. At this level also the spinal canal on the right side divided again into two, giving rise to a total of three canals. This arrangement persisted for $2-3 \mathrm{~mm}$. whereafter serial sections showed a progressive change in histological structure, only in reverse order to that seen in the cephalic half of the plaque (levels $E$ and F). Caudal to the plaque the atrophy of the cord was confirmed, this presumably being a secondary mechanical effect of the hamartoma.

\section{DISCUSSION}

The hamartomatous component of the lesion which has been described is developmental in origin since it appears to have interfered with the normal mode? of closure of the embryonic neural tube. Such $a \varrho$ concept is not new, as Patten (1953) demonstrated the presence of a localized overgrowth of neuro- 8 ectoderm in human dysraphic spinal cords. Thiso feature was confirmed experimentally in the rat by Warkany, Wilson, and Geiger (1958).

It is suggested that the present case is a variant of diastematomyelia, a form of spinal dysraphia in which the cord is split longitudinally. Good accounts of it are given by Herren and Edwards (1940), Cameron (1957), and Willis (1958). The usual appearance of diastematomyelia on cross-section is for there to be two separate cords, each with its own spinal canal together with a single anterior and posterior horn. There are thus four sets of lateral nerve roots, none arising from the medial aspects of the adjacent cords.

The manner of development of this malformation on the basis of a localized overgrowth of neuroectoderm is illustrated diagrammatically in Figure 2. It is thought that undue separation of the borders of the embryonic neural plate secondary to such abnormal growth can completely inhibit the formation of the neural tube, resulting in an open myelocoele (Figure 2B). Alternatively, the infolding process within the plate may occur, but because of their separation the borders fuse with a mid line outgrowth rather than with each other, producing a diastematomyelia. 
A
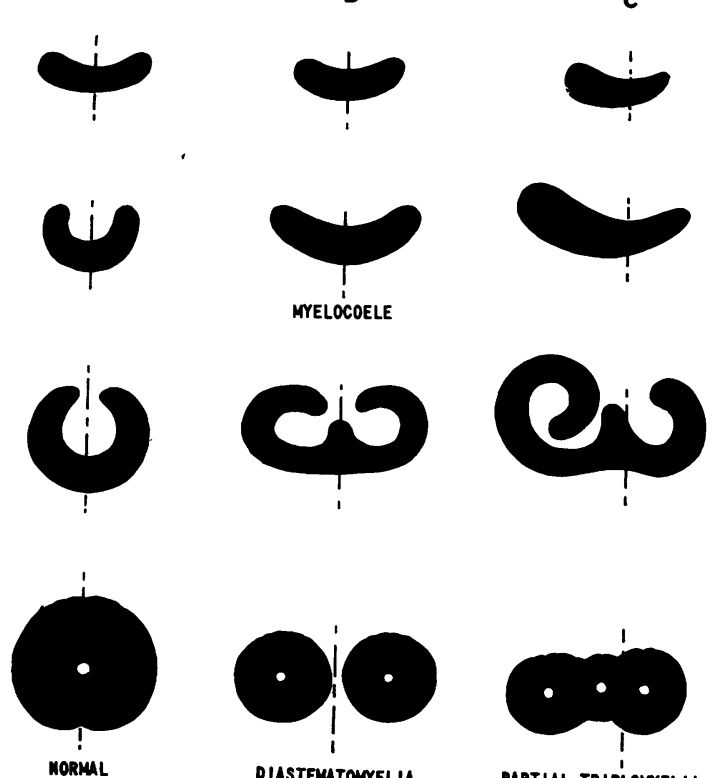

DIASTEMTOMYELIA
C
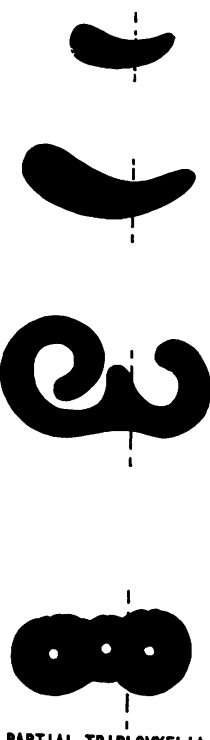

PARTIAL TRIPLOUYELIA

FIG. 2. Diagrams to illustrate:

$A$ The normal process of formation of the embryonic neural tube from the neural plate.

$B$ Widening of the neural plate because of an abnormal overgrowth of neuroectoderm may completely inhibit tube formation and result in a myelocoele. Alternatively the borders of the plate may infold independently, producing a diastematomyelia.

C In the present case it is postulated that neuroectodermal overgrowth predominated on the right side to an extent sufficient to result in an uncompleted triplication of the cord in the manner shown.

In the present case, incomplete division appears to have occurred twice, giving rise to three canals, three posterior and four anterior horns. The amount of tissue is greatly in excess of normal, and also more than that seen in the usual form of diastematomyelia. It is suggested (Fig. 2C) that a preponderance of the overgrowth on the right provoked a second additional incomplete division on this side, resulting in what could be termed a partial triplomyelia.

It is now well established that the development of the embryonic ectoderm and męsoderm is mutually interdependent (Lash, 1964) and malformations which affect the one type of cell often bring about changes in the differentiation of the other. As von Recklinghausen's disease is basically a fault of neuroectodermal growth one would consequently expect to find an assosiation with various mesodermal malformations.

Osseous involvement in neurofibromatosis has been reviewed by Holt and Wright (1948). Distinction must, however, be made between bony changes present at birth and those that develop in the adult; the latter are usually due to erosion of the bone by adjacent soft tissue tumour or are secondary to osteomalacia (Dent, 1952; Swann, 1954). On the other hand, some bony defects, especially of the thoracic spine, are purely developmental in origin and may well present in childhood as a thoracic kyphosis or scoliosis (Allibone, Illingworth, and Wright, 1960).

That development of mesoderm and neuroectoderm may be involved together in neurofibromatosis is shown by the occurrence of congenital vertebral anomalies with meningocele formation. These meningoceles are again characteristically in the thoracic region and protrude laterally through the intervertebral foramen. The first such case was described by Pohl in 1933, but Robinson in 1964 collected 47 examples of intrathoracic meningoceles from the literature, including three of his own. Of these neurofibromatosis was recorded in $70 \%$, though it was thought that the proportion would have been higher had they been re-assessed at a later date. It is interesting that by far the commonest form of meningocele unassociated with neurofibromatosis is a dorsal protrusion of meninges through a defect of the spinal laminae, and the thoracic region is a comparatively uncommon site for this (Ingraham and Matson, 1954; Doran and Guthkelch, 1961; Laurence, 1964). Indeed only one case of meningocele outside the thoracic region with neurofibromatosis has been recorded (Sammons and Thomas, 1959). Several small lateral lumbar meningoceles were demonstrated by myelography in this case. Knapp (1934) noted an association of neurofibromatosis with cerebral meningocele and spina bifida, but subsequent writers consider this to be a coincidental finding.

Another possible type of congenital malformation is that which is confined to the neuroectodermal tissues as in the present case. Lichtenstein (1940) described three cases of spinal dysraphia without bony involvement, but there is no doubt that this is a comparatively rare phenomenon. None of the three cases was associated with von Recklinghausen's disease. Rodriguez and Berthrong (1966) found syringomyelia in $20 \%$ of their series of neurofibromatosis of the central type. This defect may be a primary developmental fault, but is much more likely to be a secondary effect of a tumour within the central nervous system (Poser, 1956).

Our own case supports the contention that an embryonic hamartomatous growth may produce dysraphia. The level at which the lesion occurred (mid-thoracic) is consistent with the predilection of 
the thoracic region as a site for lateral meningoceles and vertebral anomalies in von Recklinghausen's disease, though these lesions were not present in this instance.

Finally, clinical interest centres on the possibility, albeit a rare one, that a patient with generalized neurofibromatosis and unexplained neurological signs may have a congenital malformation of the spinal cord. Such a diagnosis cannot apparently be excluded by the onset of neurological impairment in later life. Moreover straight radiographs and myelography may give no indication of its presence. It is as well to remember that in cases of neurofibromatosis the mid-thoracic region is the most likely site for malformation, and that this is unfortunately notoriously difficult to visualize adequately on a spinal myelogram.

\section{SUMMARY}

The case is described of a 63-year-old woman with generalized neurofibromatosis who had neurological signs referable to the legs for six months prior to death. Necropsy revealed a hamartomatous expansion of the spinal cord at T.5, 6, and 7. Histological examination showed a peculiar congenital malformation, with at one level three spinal canals, three posterior and four anterior horns.

Attention is drawn to the following points:-

1 The lesion supports the hypothesis that spinal dysraphia may result from an overgrowth of embryonic neuroectoderm.

2 Though hamartomatous lesions in the adult are a characteristic of neurofibromatosis, this case is probably unique in that the tumour grew at a stage early enough to interfere with the normal embryogenesis of the spinal cord.

3 There is an association between neurofibromatosis and malformation of the thoracic vertebral column. Such anomalies usually involve skeletal structures and occasionally the meninges. In this case the thoracic spinal cord alone was malformed.

Our thanks are due to Mrs. C. Worsley for technical assistance with the histological preparations, and to Mr. R. Neave for drawing the diagrams. We are especially grateful to Professor P. O. Yates for his advice and criticism, and to Dr. H. T. Howat and Mr. H. B. Torrance for granting access to their case records.

\section{REFERENCES}

Allibone, E. C., Illingworth, R. S., and Wright, T. (1960). Neurofibromatosis (von Recklinghausen's disease) of the vertebral column. Arch. Dis. Child., 35, 153-158.

Cameron, A. H. (1957). Malformations of the neuro-spinal axis, urogenital tract and foregut in spina bifida attributable to disturbances of the blastopore. J. Path. Bact., 73, 213-221.

Dent, C. E. (1952). Rickets and osteomalacia from renal tubule defects. J. Bone Jt Surg., 34B, 266-274.

Doran, P. A., and Guthkelch, A. N. (1961). Studies in spina bifida cystica. I. General survey and re-assessment of the problem. J. Neurol. Neurosurg. Psychiat., 24, 331-345.

Gardner, W. J., and Frazier, C. H. (1930). Bilateral acoustic neurofibromas. Arch. Neurol. Psychiat. (Chic.), 23, 266-302.

Herren, R. Y., and Edwards, J. E. (1940). Diplomyelia (duplication of the spinal cord). Arch. Path., 30, 1203-1214.

Holt, J. F., and Wright, E. M. (1948). The radiologic features of neurofibromatosis. Radiology, 51, 647-664.

Ingraham, F. D., and Matson, D. D. (1954). Neurosurgery of Infancy and Childhood. Thomas, Springfield, Illinois.

Knapp, A. A. (1934). Von Recklinghausen's disease. Med. Rec. (N.Y.), 139, 62-64.

Lash, J. W. (1964). Normal embryology and teratogenesis. Amer. J. Obstet. Gynec., 90, 1193-1207.

Laurence, K. M. (1964). The natural history of spina bifida cystica: detailed analysis of 407 cases. Arch. Dis. Child., 39, 41-57.

Lichtenstein, B. W. (1940). 'Spinal dysraphism'-spina bifida an myelodysplasia. Arch. Neurol. Psychiat. (Chic.), 44, 792-810.

(1949). Neurofibromatosis (von Recklinghasen's disease of the nervous system). Ibid., 62, 822-839.

Obrador, S. (1963). Some neurosurgical aspects of the so-called phakomatoses. J. Neurosurg., 20, 296-302.

Patten, B. M. (1953). Embryological stages in the establishing of myeloschisis with spina bifida. Amer. J. Anat., 93, 365-395.

Pohl, R. (1933). Meningokele im Brustraum unter dem Bilde ein intrathorakalen Rundschattens. Röntgenpraxis, 5, 747-749.

Poser, C. M. (1956). The Relationship between Syringomyelia an Neoplasm. Thomas, Springfield, Illinois.

Recklinghausen, F. D. von (1882). Ueber die multiplen Fibrome de Haut und ihre Beziehung zu den multiplen Neuromen. Hirsch wald, Berlin.

Robinson, R. G. (1964). Intrathoracic meningocele and neuro fibromatosis. Brit. J. Surg. 51, 432.437.

Rodriguez, H. A., and Berthrong, M. (1966). Multiple primar intracranial tumors in von Recklinghausen's neurofibromatosis Arch. Neurol. (Chic.), 14, 467-475.

Sammons, B. P., and Thomas, D. F. (1959). Extensive lumbar . meningocele associated with neurofibromatosis. Amer. $J$. Roentgenol., 81, 1021-1025.

Swann, G. F. (1954). General softening of bone due to metabolic causes. IV. Pathogenesis of bone lesions in neurofibromatosis. Brit. J. Radiol., 27, 623-629.

Turner, O. A., and Gardner, W. J. (1938). Familial involvement of 으 the nervous system by multiple tumors of the sheaths and $\mathbb{D}$ enveloping membranes. Amer. J. Cancer, 32, 339-360.

Van der Hoeve, J. (1932). Eye symptoms in phakomatoses. Trans. ophthal. Soc. (U.K.), 52, 380-401.

Warkany, J., Wilson, J. G., and Geiger, J. F. (1958). Myeloschisis and myelomeningocele produced experimentally in the rat. J. comp. Neurol., 109, 35-54.

Willis, R. A. (1958). The Borderland of Embryology and Pathology Butterworth, London.

- (1965). The hamartomatous syndromes: their clinical, pathological and fundamental aspects. Med. J. Aust., 1, 827-833.

Worster-Drought, C., Dickson, W. E. C., and McMenemey, W. H (1937). Multiple meningeal and perineural tumours with analogous changes in the glia and ependyma. (Neurofibroblastomatosis). Brain, 60, 85-117. 